\title{
Exploring the synergy between along-track altimetry and tracer fronts to reconstruct surface ocean currents
}

\author{
Francesco Nenciolia,*, Graham D. Quartly ${ }^{\mathrm{a}}$ \\ ${ }^{a}$ EOSA, Plymouth Marine Laboratory, United Kingdom
}

\begin{abstract}
High-frequency along-track altimetric data only provide direct information on the geostrophic currents orthogonal to the track. A new approach is proposed that combines these across-track current estimates with directional information from remotely-sensed tracer fields, such as surface chlorophyll concentration and sea surface temperature. The analysis focuses on the South Madagascar region characterised by the strong East Madagascar Current and sharp gradients of surface tracers. The results are compared with in-situ observations from three moorings along the Jason-1 track 196. Accurate information on the total velocity direction is the key factor for obtaining accurate estimates of along-track velocities. Surface tracer fronts can be successfully used to retrieve such information, especially when currents intersect the satellite track at low incidence angles (within $\pm 60^{\circ}$ from the perpendicular direction). Errors in the reconstructed total velocities tend to grow rapidly for higher angles. Best performance is obtained by retaining information from the strongest fronts only. However, this significantly limits the resolution at which total currents can be reconstructed along the altimeter
\end{abstract}

\footnotetext{
${ }^{*}$ Corresponding author

Email address: fne@pml.ac.uk (Francesco Nencioli) 
track.

Keywords: Satellite synergy, Along-track currents, Ocean Colour CCI, Sea Surface Temperature, East Madagascar Current

\section{Introduction}

Surface ocean currents are a key component of the Earth's climate. They regulate the transport and redistribution of heat and dissolved salts, as well as the dispersion of plankton, fish larvae, nutrients and pollutants (e.g Ganachaud and Wunsch, 2000; Jönsson and Watson, 2016). They also have a significant impact on marine ecosystems since they can define fluid dynamical niches which contribute to the shaping and structuring of population distributions from phytoplankton to top predators (e.g. d'Ovidio et al., 2010; Cotté et al., 2015). As such, they have been included in the list of essential climate variables (Bojinski et al., 2014). Knowledge of their spatial patterns and temporal variability has direct implications on a broad range of socioeconomic activities, ranging from fishery and environmental management, to maritime trade and search and rescue operations.

In the last two decades, satellite altimetry has emerged as one of the main sources of observation for the investigation of surface ocean dynamics (Le Traon, 2013). Along-track observations of sea surface height (SSH) from multiple altimeters can be combined together to produce global two-dimensional fields through interpolation in space and time using optimal interpolation schemes (Le Traon et al., 1998). The gridded maps of SSH can then be used to compute the balanced component of surface ocean currents through the geostrophic balance equations. The two-dimensional surface velocity fields 
have an effective resolution of $\sim 150-200 \mathrm{~km}$ in space and 5-10 days in time (Chelton et al., 2011). Therefore, while they are capable of resolving processes from basin-scale currents down to the larger mesoscale eddies, they are unable to capture the signature of the smaller scales (100 to $10 \mathrm{~km}$ ). These include small mesoscale and submesoscale processes, which in recent years have been recognised to be critical for the ocean energy budget (e.g. Capet et al., 2008) and global biogeochemical cycles (e.g. Mahadevan, 2016). New generation altimeters based on Synthetic Aperture Radar (SAR) technology, such as the European Space Agency Sentinel-3 (https://sentinel. esa.int/web/sentinel/missions/sentinel-3), provide along-track measurements of SSH with a sampling frequency of $20 \mathrm{~Hz}$, resulting in a spatial resolution of $\sim 300 \mathrm{~m}$. Because of the noise affecting the measurements, the smallest scales of currents that can be resolved are in the range of $50 \mathrm{~km}$ in highly dynamic areas, but can increase to $100 \mathrm{~km}$ in quieter regions (Dufau et al., 2016). Therefore, although these observation are still characterised by a limited spatial (as well as temporal) resolution for the observations of processes of $\mathcal{O}(10) \mathrm{km}$ (Chavanne and Klein, 2010), they have the potential to provide information at smaller spatial scales than the gridded fields. Their main limitation is that they can only provide estimates of the velocity component perpendicular to the satellite track.

Approaches based on multi-sensor synergy have the potential to mitigate this limitation and provide the full two-dimensional velocities from alongtrack observations. Such approaches are particularly attractive in the context of the Sentinel-3 mission, which has the major advantage of having ocean colour, sea surface temperature (SST) and altimeter observations co- 
localized on the same satellite. Sequential satellite imagery of single surface ocean tracers, such as ocean colour and SST, have been already used in the past to retrieve complementary information about horizontal ocean currents. The various approaches include inverse methods based on heat conservation equation (Chen et al., 2008), neural networks (Côte and Tatnall, 1997), and Maximum Cross Correlation technique (Bowen et al., 2002; Warren et al., 2016). Furthermore, SST have been used within the framework of Surface Quasi-Geostrophy (SQG) to derive the full 3-dimensional velocities within the upper layer (e.g. Lapeyre and Klein, 2006) and, combined with SSH, to reconstruct more accurate horizontal velocity fields (Isern-Fontanet et al., 2014). (Interested readers are encouraged to read Isern-Fontanet et al. (2017) for a detailed overview of these methods.)

Here we present an exploratory study on the capability of retrieving the full velocity components along an altimeter track by exploiting the synergy between observations from different satellite sensors (i.e. across-track velocities from sea level altimetry and directional information from satellite observations of surface tracers). The study was conducted within the context of GlobCurrent (2014-2017; http://www.globcurrent.org/), an ESA-funded project specifically focussed on "advancing the quantitative estimations of ocean surface currents from satellite sensor synergies". In particular, this study aims at addressing two main questions:

1. Can the synergy between along-track altimetry and surface tracer front direction provide reliable total velocities?

2. As along-track altimetry observations are characterised by higher resolution than the mapped products, can such velocities provide dynamical 
information at scales currently not resolved in multi-satellite $2 \mathrm{D}$ surface velocity fields?

\section{Data and Methods}

\subsection{The synergistic approach}

As surface tracers are continuously stirred by the ocean circulation, their fields are characterised by fronts predominantly aligned with the direction of the main currents (e.g. Lehahn et al., 2007; d'Ovidio et al., 2009). Therefore, front directions derived from surface maps of chlorophyll and temperature can be combined with the across-track velocities derived from along-track altimetry observations to compute total surface velocities. The method investigated in this study combines the direction of chlorophyll and temperature fronts, $\alpha_{\text {front }}$ (here defined as the angle between a front axis and the across-track velocity vector) and the altimetry-based across-track velocities $V_{\text {across }}$, to compute the along-track velocities $V_{\text {along }}$ as

$$
V_{\text {along }}=V_{\text {across }} \tan \left(\alpha_{\text {front }}\right)
$$

so that the resulting total velocity vector, $\boldsymbol{V}$, will have direction parallel to the front and the same across-track component as measured from altimetry (see Figure 1).

By hypothesising that the fronts are predominantly aligned with horizontal surface currents our approach accepts two main assumptions: a) that surface chlorophyll and temperature act as passive tracers - that is, variations due to local production, in the case of chlorophyll, and surface exchanges with the atmosphere, in the case of temperature, are negligible compared with 


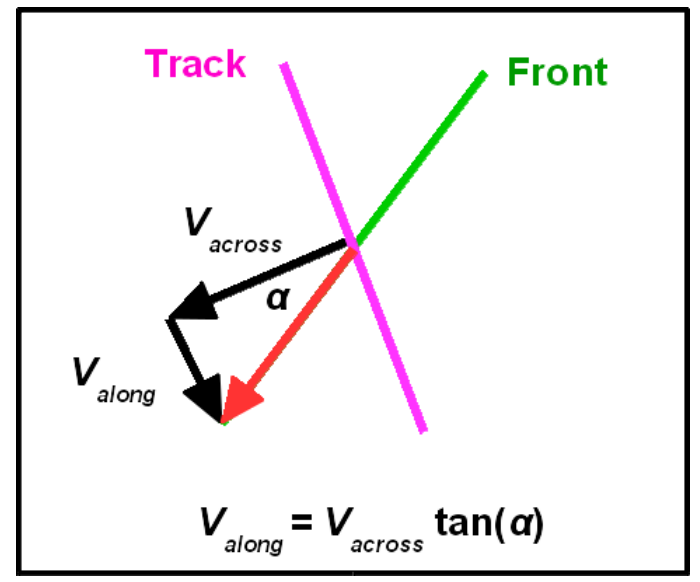

Figure 1: Diagram illustrating the geometry of the different terms in equation 1: front axis and satellite track are shown in green and magenta respectively. The total velocity vector, $\boldsymbol{V}$, is shown in red. $\alpha_{\text {front }}$ varies between -90 and 90 degrees, so that the sign of $V_{\text {along }}$ is automatically determined by that of $V_{\text {across }}$ (i.e. for a negative $\alpha_{\text {front }}, V_{\text {along }}$ is positive(southward) when $V_{\text {across }}$ is negative(westward), and vice-versa).

those due to advection, and b) that tracer advection is mostly 2-dimensional - that is, variations due to vertical motions (e.g. upwelling) are of second order compared with the horizontal ones. The validity of these assumptions will be discussed and assessed in Sections 2.4 and 3.1.

\subsection{Region of study}

The general principles of the method can be applied to any combination of remotely sensed single velocity component and surface tracer front direction. In this study specifically, we applied the method in the South Madagascar region (Figure 2, top left) combining surface velocities from Jason-1 with front directions from multi-satellite composite observations of surface chlorophyll and sea surface temperature. These particular choices of region and datasets were based on a series of favourable characteristics 

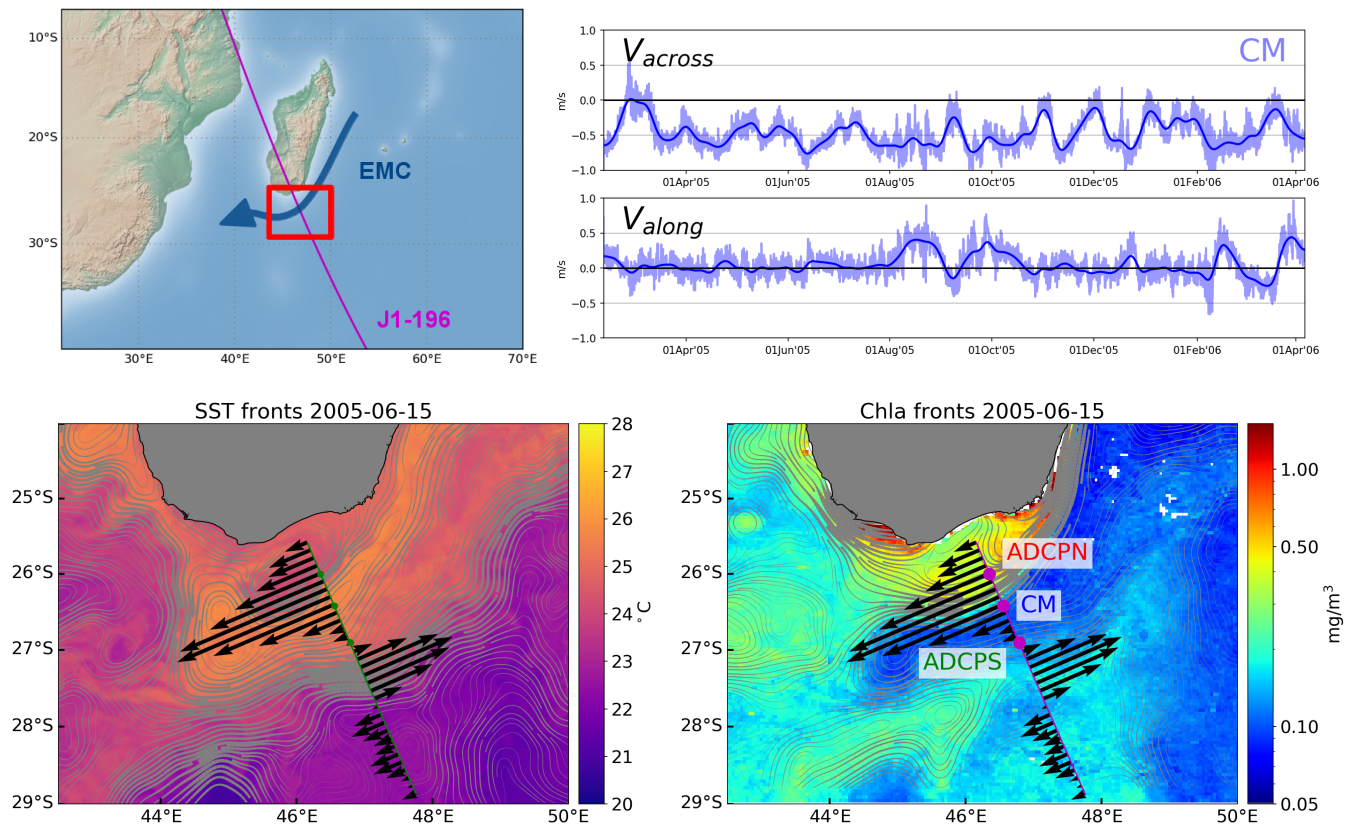

Figure 2: (Top left) Geographical map of the south Madagascar region with the East Madagascar Current (EMC, blue), Jason-1 196 satellite track (J1-196, magenta) and area of focus of the study (red rectangle) highlighted. (Top right) Time series of across-track and along-track velocity components recorded at the $\mathrm{CM}$ ADCP mooring. In light blue are the hourly measurements, while in dark blue the two moving-averaged components. (Bottom left) MUR surface temperature field for 15 June 2005. The grey contours mark the direction of the tracer fronts with each line width proportional to the front strength. J1-196 track (green line) and observed across-track velocities (black vectors) for the same day are also shown. (Bottom right) Same as bottom left, but for OC_CCI 7-day composite chlorophyll concentration. Magenta circles indicate the locations of the 3 ADCP moorings used in the study.

for testing the proposed approach, which include: a) an intense flow almost perpendicular to the Jason-1 196 satellite track (hereafter J1-196) due to the presence of the East Madagascar Current (EMC); b) strong surface gradients in both temperature and chlorophyll; c) three moorings deployed from 
February 2005 to April 2006 along the J1-196 track (Quartly, 2006), which provide in-situ velocity observations for validating the results. Although the EMC is a strong western boundary current, the flow field to the south of Madagascar is marked by high mesoscale variability. This has been observed in altimetry, drifters and model output (Quartly et al., 2006), with a good correspondence between features seen in gridded altimetry products and by infra-red and ocean colour sensors (Quartly and Srokosz, 2003). de Ruijter et al. (2004) has shown pairs of large counter-rotating eddies generated by the intense flow and shear within this region. Westward-propagating features are noted in both SST analysis (Quartly and Srokosz, 2002) and in animations of chlorophyll composites (Quartly and Srokosz, 2004). The region is less cloudy than the area of the Agulhas Retroflection to the south of South Africa, so that useful short-period composites of chlorophyll and temperature can usually be achieved for this area.

\subsection{Datasets}

The analysis is based on the SSALTO/DUACS filtered altimetry data (SSALTO/DUACS User Handbook, 2016) collected along the J1-196 track from February 2005 to April 2006 (Figure 2, bottom). The data were obtained from AVISO+ (https://www.aviso.altimetry.fr/), but after April 2017, processing and distribution of altimetry products moved to the European Copernicus Marine Environment Monitoring Service (CMEMS; http: //marine.copernicus.eu). The data have spatial resolution of $14 \mathrm{~km}$ and temporal resolution of 10 days. $V_{\text {across }}$ components have been computed from along-track absolute dynamic topography using a 3rd order, 3-point stencil centre differencing (Arbic et al., 2012). Other processing of the Jason-1 data 
are available, differing in spatial sampling and correlations applied. The particular altimetric dataset selected here is not critical because, as will be shown later, the errors in the across-track component have a smaller effect than the uncertainty in directional information.

The three ADCP moorings were deployed at $46^{\circ} 21^{\prime} \mathrm{E}, 26^{\circ} 00^{\prime} \mathrm{S}(\mathrm{ADCPN})$, $46^{\circ} 33^{\prime} \mathrm{E}, 26^{\circ} 25^{\prime} \mathrm{S}(\mathrm{CM})$ and $46^{\circ} 47^{\prime} \mathrm{E}, 26^{\circ} 54^{\prime} \mathrm{S}$ (ADCPS) (Figure 2, bottom right). ADCPN and ADCPS were both equipped with an upward-facing $75 \mathrm{kHz}$ Acoustic Doppler Current Profiler (ADCP) at $500 \mathrm{~m}$ depth. CM included a series of RCM 11 discrete self-recording current meters. All moorings provided time-series of hourly measurements of velocity at $\sim 140$ $\mathrm{m}$ depth. The time-series were moving averaged with a Gaussian window with full width at half maximum (hereafter FWHM) of 6 inertial periods (one inertial period ranges between 26 and 27 hours at the mooring latitudes) to remove the signal associated with high-frequency processes, such as tidal and inertial motions. Comparison between the averaged time-series of $V_{\text {across }}$ from moorings and from the J1-196 track shows a good fit (correlation coefficient $\mathrm{r}=0.88$, Figure 3 ). Mooring velocities are usually weaker than the remote sensing ones, in part due to the smoothing and in part due to the depth difference between the two measurements. Sensitivity analysis showed only minor variations in the correlation between $V_{\text {across }}$ from altimetry and that from the moorings averaged with shorter time windows. Thus, we decided to use a 6-inertial period FWHM to have a temporal window with analogous width to the one used for reconstructing the composite tracer fields from which front directions are derived (see next two paragraphs). The correlation coefficients and root mean square errors (RMS) for each individual 

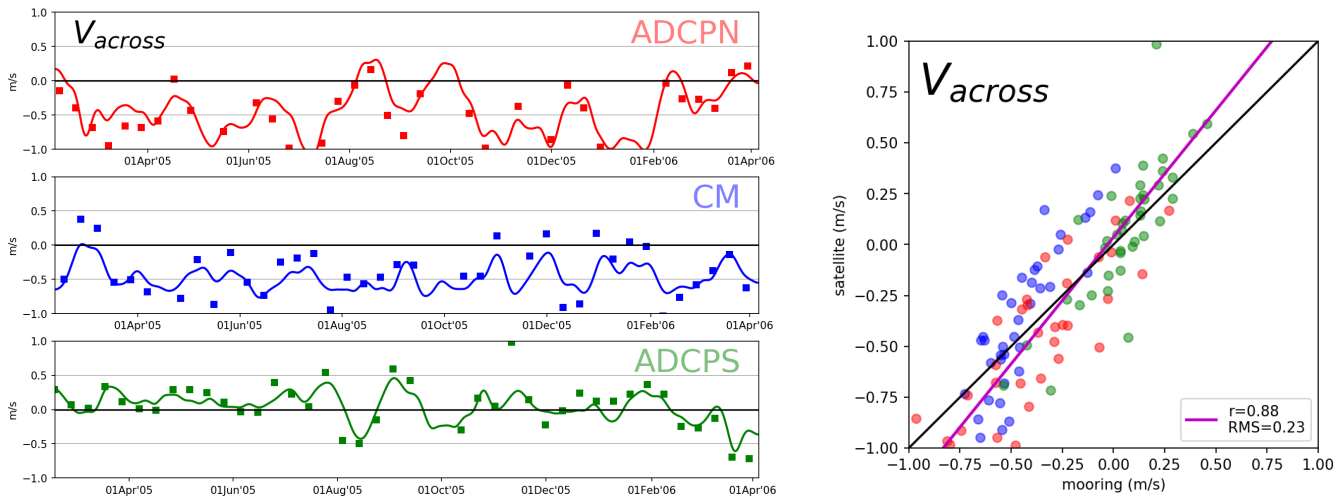

Figure 3: (Left) Time-series of $V_{\text {across }}$ from satellite (squares) and moving-averaged ADCP observations (solid line) for the ADCPN, CM and ADCPS moorings (in red, blue and green respectively). The same colors will be associated with these three moorings throughout the rest of the paper. (Right) Correlation between satellite and mooring $V_{\text {across }}$.

mooring site (not shown) are similar to those showed in Figure 3 for all three moorings combined. However, the regression slope for CM is slightly steeper than for ADCPN and ADCPS, suggesting some spatial variability in the correlation between in-situ and satellite observations. On the other hand, correlations obtained for different flow direction show similar regression lines to Figure 3 for currents at both low and high incidence angle with respect to the satellite track $\left(|\alpha|<45^{\circ}\right.$ and $|\alpha|>45^{\circ}$, respectively). At the same time, the correlation coefficient for high incidence angles is much lower $(\mathrm{r}=0.66)$ while the RMS remains $\sim 0.2 \mathrm{~m} \mathrm{~s}^{-1}$ (despite the narrower range of $V_{\text {across }}$ values), indicating a less accurate correlation between in-situ and satellite velocities for flows almost parallel to the satellite track. Both aspects have important implications for our analysis and will be discussed in detail in Section 3.

Sea surface temperature is from the version 4.1 Multi-scale Ultra-high Resolution (MUR) dataset (JPL MUR MEaSUREs Project, 2015) distributed 
by the Physical Oceanography Distributed Active Archive Center (PODAAC; https ://podaac.jpl . nasa.gov/dataset/MUR-JPL-L4-GLOB-v4 .1) (Figure 2 bottom left). MUR is a Group for High Resolution Sea Surface Temperature (GHRSST; https://www.ghrsst.org/) level 4 SST composite analysis produced daily on a global 0.01 degree grid $(\sim 1 \mathrm{~km}$ spatial resolution at the latitudes of the region of study) using wavelets as basis functions in an optimal interpolation approach. The analysis is based upon nighttime GHRSST L2P skin and subskin SST observations from several instruments. The resulting SST values are an estimate of the "foundation temperature" (i.e. the near-surface temperature below the extent of diurnal fluctuation due to the surface solar heating), corresponding to $\sim 10 \mathrm{~m}$ depth.

Chlorophyll concentrations were provided by the Ocean Colour-Climate Change Initiative project of the European Space Agency (ESA's OC_CCI product, Version 2.0; http: //www .esa-oceancolour-cci.org/) (Grant et al., 2015). This product was created by merging satellite data from sensors MERIS, MODIS, and SeaWiFS, after shifting the wavelength bands and correcting the bias between the sensors. It consists of a global daily level 3 binned data set provided on a sinusoidal grid at $4 \mathrm{~km}$ resolution. Sevenday composite surface fields were obtained by averaging all the observations available for each pixel within 3 days before and 3 days after the date of each J1-196 passage (Figure 2, bottom right). Using 7-day composites drastically reduced the number of missing pixels due to cloud coverage and, at the same time, only moderately smoothed the main chlorophyll patterns which preserved their general shape and orientation. 


\subsection{Front direction}

Estimates of the front direction were directly derived as the perpendicular direction to the total horizontal gradients (Figure 2, bottom). The gradients were computed from the surface tracer maps by central differencing, and then smoothed with a 2-dimensional isotropic Gaussian moving average filter (FWHM of $\sim 40 \mathrm{~km}$ ) to reduce the noise and highlight the gradients associated with scales analogous to those from along-track altimetry. In case of chlorophyll, gradients were computed from the base 10 logarithm of the surface concentrations. This allowed the identification not only of the strong gradients between coastal and open ocean waters at the southern tip of Madagascar, but also of the open ocean ones characterised by much lower chlorophyll variations. Values at the location of each altimetry observation along the J1-196 track were obtained through nearest neighbour interpolation.

As for $V_{\text {across }}$, the accuracy of front-based velocity directions (and thus the validity of the assumptions described in Section 2.1) was assessed by comparing the directions of in-situ velocities with those of chlorophyll and SST fronts. Figure 4 shows the histograms of the angle difference between the two. All the histograms peak around $\Delta \alpha=0$, indicating that overall the fronts tend to be aligned with the horizontal velocities. Chlorophyll fronts better represent ADCP directions than SST fronts, in particular at the mooring locations closer to the Madagascar coast where the front is stronger (Figure 2, bottom right). At the same time, the relatively broad widths of the histograms indicate that our initial hypothesis is not always respected and that differences between front and velocity directions can often be quite large. 
The error associated with front-based velocity directions can be quantified by averaging the 25 and 75 percentiles of the cumulative distributions, resulting in $\sim 20^{\circ}$. Despite previous studies having shown that the variability in spatial correlation between SST and SSH anomalies is linked to the seasonal cycle of the mixed layer depth (e.g. Jones et al., 1998), no clear temporal patterns have been identified from the analysis of the time-series of $\Delta \alpha$ (not shown). By further smoothing the gradients in both time (moving average with 10 day FWHM) or space (80 km FWHM) the alignment between front and ADCP velocities is increased near the coast (higher histogram peaks around $\Delta \alpha=0$ ), but the overall accuracy noticeably decreases due to the excessive smearing of the weaker gradients further offshore, resulting in biased peaks and broader histograms (not shown).

\section{Results}

\subsection{Accuracy of the Proposed Approach}

The first step of the analysis consisted of investigating the reliability of the approach proposed in Section 2.1. This was achieved by first assessing the accuracy of the $V_{\text {along }}$ obtained from equation 1 using $V_{\text {across }}$ and $\alpha$ from all the available observations from the 3 ADCP moorings. Normally distributed random errors $\left(\delta_{V}\right.$ and $\left.\delta_{\alpha}\right)$ were added to the two parameters to evaluate the impact of the uncertainties associated with remote sensing observations and their misfit with respect to in-situ observations for retrieving $V_{\text {along }}$ from Equation 1. Standard deviations for $\delta_{V}$ and $\delta_{\alpha}$ were obtained from the comparisons between in-situ and remote sensing observations showed in Figures 3 and 4 , and were set to $\sigma_{V}=0.2 \mathrm{~m} \mathrm{~s}^{-1}$ and $\sigma_{\alpha}=20^{\circ}$, respectively. 

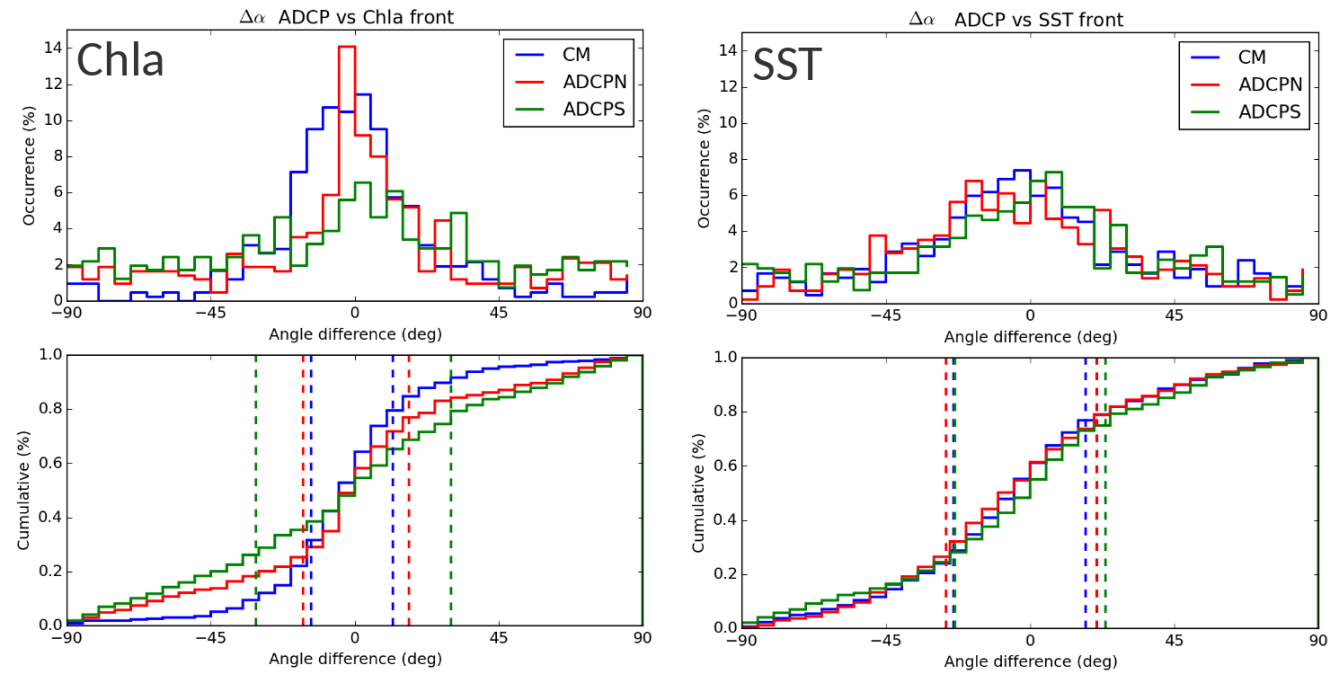

Figure 4: (Top row) Histogram of angle difference between ADCP velocity and chlorophyll (left) and SST (right) front directions $\left(\Delta \alpha=\alpha_{\text {front }}-\alpha_{A D C P}\right)$ for the three moorings. The colours identify the various moorings as in Figure 3. $\Delta \alpha=0$ degrees if ADCP velocities and front axis are parallel; $\Delta \alpha= \pm 90$ degrees if ADCP velocities and front axis are perpendicular to each other. (Bottom row) Same as top row but for cumulative distributions instead. Vertical dashed lines indicate the 25 and 75 percentiles.

The correlations between the reconstructed and observed $V_{\text {along }}$ are shown in Figure 5. The three panels show results in the case of a random error added to the velocity component only $\left(V_{\text {across }}+\delta_{V}, \alpha\right.$; left), to the velocity direction only ( $V_{\text {across }}, \alpha+\delta_{\alpha}$; middle), and to both parameters at the same time ( $V_{\text {across }}+\delta_{V}, \alpha+\delta_{\alpha}$; right). Because of the added errors, the values of reconstructed $V_{\text {along }}$ can vary substantially from the observed ones, so that the resulting regression curves (gray line) deviates from the 1:1 correlation (black line), the correlation coefficients are low and the RMS are high in all three cases. The distribution of the absolute difference between observed and re- 

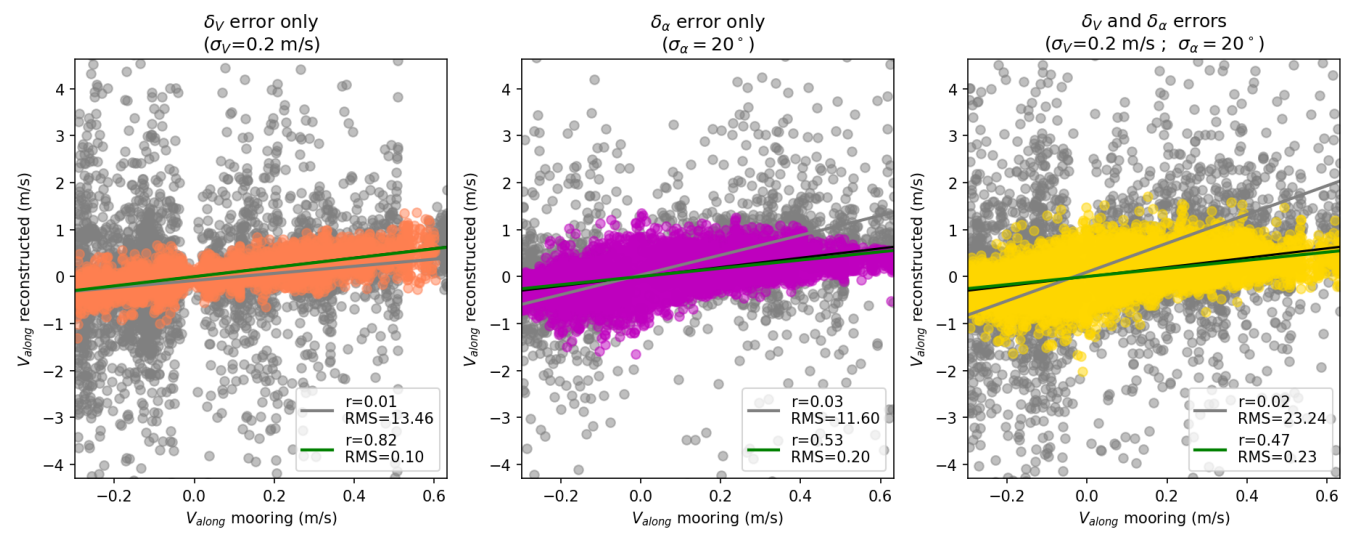

Figure 5: Correlation between in-situ $V_{\text {along }}$ and that reconstructed from in-situ $V_{\text {across }}$ and $\alpha$ with normally distributed random errors added in various combinations: (left) error on $V_{\text {across }}$ only; (middle) error on $\alpha$ only; (right) errors on both parameters. The standard deviations for the two errors $\left(\sigma_{V}\right.$ and $\left.\sigma_{\alpha}\right)$ where derived from Figures 3 and 4 (see main text). The gray lines are the regression curves for all observations available (gray circles). The green lines are the regression curves for observations with $\left|\alpha+\delta_{\alpha}\right| \leq 60^{\circ}$ only (coloured circles). The black lines mark the 1:1 correlation.

constructed $V_{\text {along }}$ with respect to $V_{\text {across }}+\delta_{V}$ and $\alpha+\delta_{\alpha}$ show that the largest errors occur at observed high incidence angles (mostly above $60^{\circ}$ and below $-60^{\circ}$, Figure 6). Indeed, by excluding the observations with $\left|\alpha+\delta_{\alpha}\right|>60^{\circ}$ from the analysis in Figure 5 (gray circles), the regression curves (green line) become very close to the 1:1 correlation, the correlation coefficients drastically increase and the RMS drop to values analogous to the ones observed for $V_{\text {across }}$ in Figure 3. The largest improvements occur for $V_{\text {along }}$ reconstructed when the random error is added to $V_{\text {across }}$ only (Figure 3, left), indicating that, among the two, the error associated with $\alpha$ has the larger impact on the accuracy of the reconstructed $V_{\text {along }}$.

Analogous results can be inspected more visually by reconstructing $V_{\text {along }}$ 


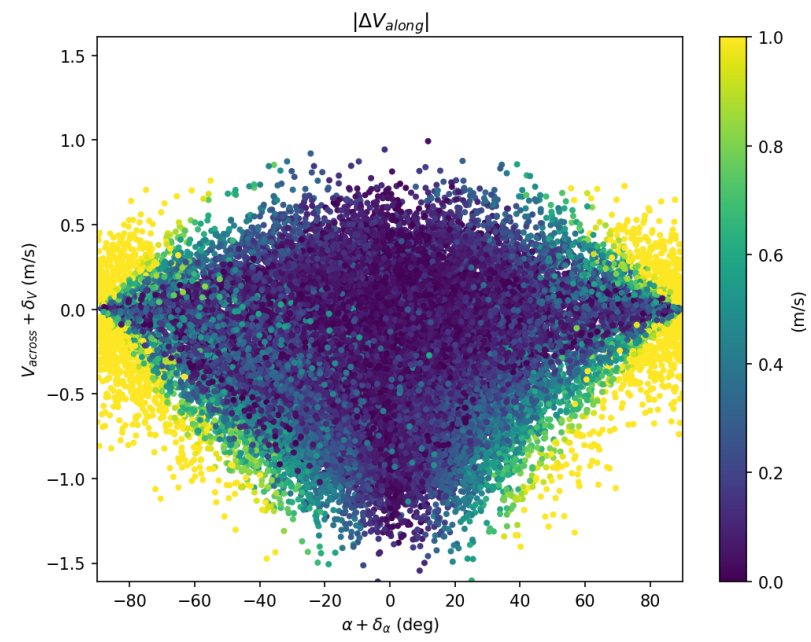

Figure 6: Distribution of the absolute difference between the observed and reconstructed values of $V_{\text {along }}$ from Figure 5 with respect to $V_{\text {across }}+\delta_{V}$ and $\alpha+\delta_{\alpha}$.

using the velocity directions directly retrieved at the location of the three moorings from ADCP observations $\left(\alpha_{A D C P}\right)$ and the $V_{\text {across }}$ from the J1-196 track. Comparison with the in-situ $V_{\text {along }}$ showed mostly good agreement (Figure 7). Large discrepancies between reconstructed and observed velocities occur for weak satellite $V_{\text {across }}$, usually associated with high $\left|\alpha_{A D C P}\right|$ values. Reconstructed total velocities at high $\left|\alpha_{A D C P}\right|$ can be of opposite direction to the measured ones. This is due to the inaccuracies in the satellite observations, which can result in remote sensing $V_{\text {across }}$ components of opposite sign in case of weak $V_{\text {across }}$ flows (i.e. small along-track SSH gradients), as it is typical at those angles. Indeed, correlation coefficients at all moorings greatly improve if only the observations with $\left|\alpha_{A D C P}\right| \leq 60^{\circ}$ are considered. Our results indicate that: i) equation 1 is accurate for most of the total velocity directions; and ii) equation 1 has inherent limitations when 

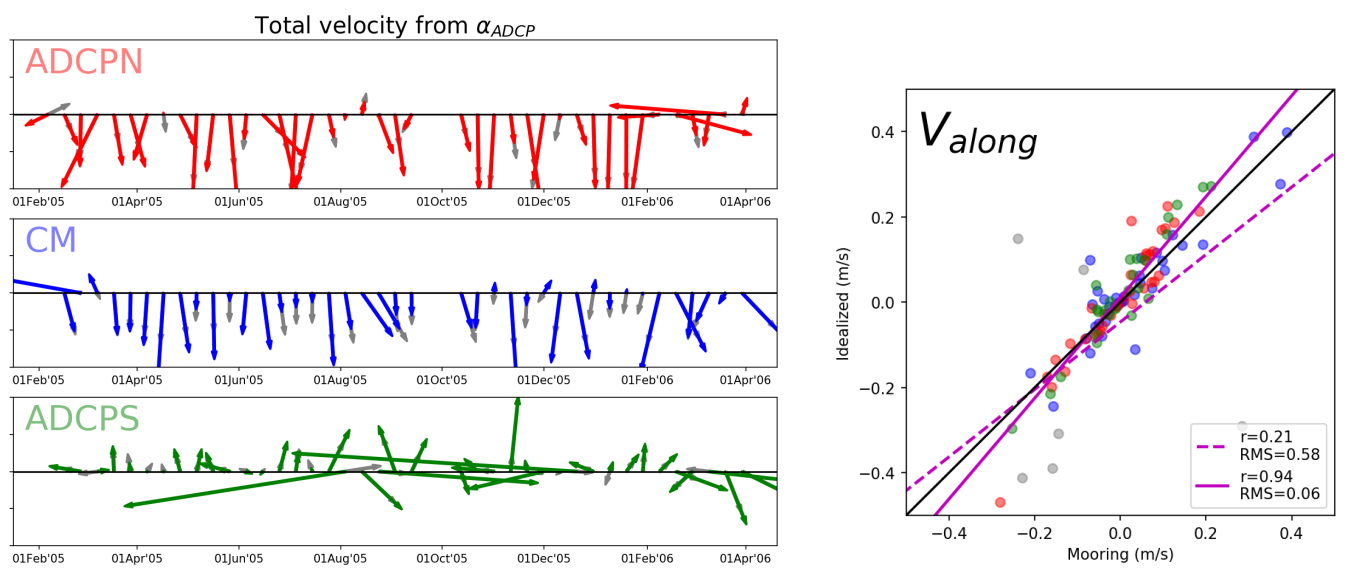

Figure 7: (Left) Time-series of measured and reconstructed $\boldsymbol{V}$ vectors (grey and colour, respectively) at the three mooring sites. The $\mathrm{x}$-axis is parallel to the satellite track with the North to the left. The $V_{\text {across }}$ component of $\boldsymbol{V}$ is from satellite observations. $V_{\text {along }}$ has been computed from equation 1, combining $V_{\text {across }}$ and the ADCP velocity direction, $\alpha_{A D C P}$. (Right) Correlation between $V_{\text {along }}$ observed at the moorings and the ones reconstructed using $\alpha_{A D C P}$. Dashed magenta line represents the linear fit using all data; solid magenta line represents the fit discarding the data with observed $\left|\alpha_{A D C P}\right|>60^{\circ}$ (grey circles). Note that some of the values used for the fit are outside the axes limits. The colours identify the various moorings as in Figure 3.

total velocity directions become almost parallel to the satellite track.

\subsection{Implementation and Validation}

For each day with J1-196 observations, $V_{\text {along }}$ has been computed from equation 1 combining satellite $V_{\text {across }}$ and the $\alpha_{\text {front }}$ obtained from the surface tracer field as described in Section 2.4. As an example, the reconstructed total velocity vectors, $\boldsymbol{V}$, for 15 June 2005 are shown in Figure 8. Although in most cases the direction of $\boldsymbol{V}$ seems to match the underlying patterns of the surface tracers, there are situations where the $\boldsymbol{V}$ vectors show unrealis- 
tic patterns. In particular, strong reconstructed velocities, often arranged in sequences of diverging/converging vectors, occur when $\alpha_{\text {front }}$ is almost parallel to the satellite track. Such patterns are associated with the contours of weaker along-flow gradients (compared with the across-stream ones) which develop as water patches with higher temperature or chlorophyll concentration protrude into regions of lower values (and vice-versa). Because of that, such gradients are not aligned with the flow field. Examples of such gradients can be observed at $\sim 26^{\circ} \mathrm{S}, \sim 46.5^{\circ} \mathrm{E}$ in Figure 8 in both chlorophyll and SST fields (likely due to the westward advection of patches of colder, chlorophyll-rich waters influenced by the flow of the EMC further off-shore), and at $\sim 27.5^{\circ} \mathrm{S}, \sim 47^{\circ} \mathrm{E}$ in the chlorophyll field only. The unrealistically high $V_{\text {along }}$ obtained from the $\alpha_{\text {front }}$ of such along-flow fronts have a clear impact on the accuracy of the proposed method, strongly reducing the correlations between observed and reconstructed $V_{\text {along }}$, as well as total velocity magnitude (correlation coefficients $\mathrm{r}<0.25$ and RMS $>1.5 \mathrm{~m} \mathrm{~s}^{-1}$; Figure 10).

As along-flow front directions are not aligned with the underlying velocity field, the associated $\alpha_{\text {front }}$ values should not be included in the analysis. As discussed in Section 2.4, further smoothing in either space or time cannot be used to remove such features. An alternative approach is to remove the unrealistically high values after $V_{\text {along }}$ has been computed. Thresholds for such values have been defined based on a combination of the maximum values of $V_{\text {along }}$ component and total velocity magnitude, $\|\boldsymbol{V}\|$, obtained from the moving-averaged in-situ observations (0.63 and $1.17 \mathrm{~m} \mathrm{~s}^{-1}$, respectively; Figure 9). It is worth noting that based on the relation in Figure 3, these values likely underestimate the actual thresholds. However, as discussed in the next 

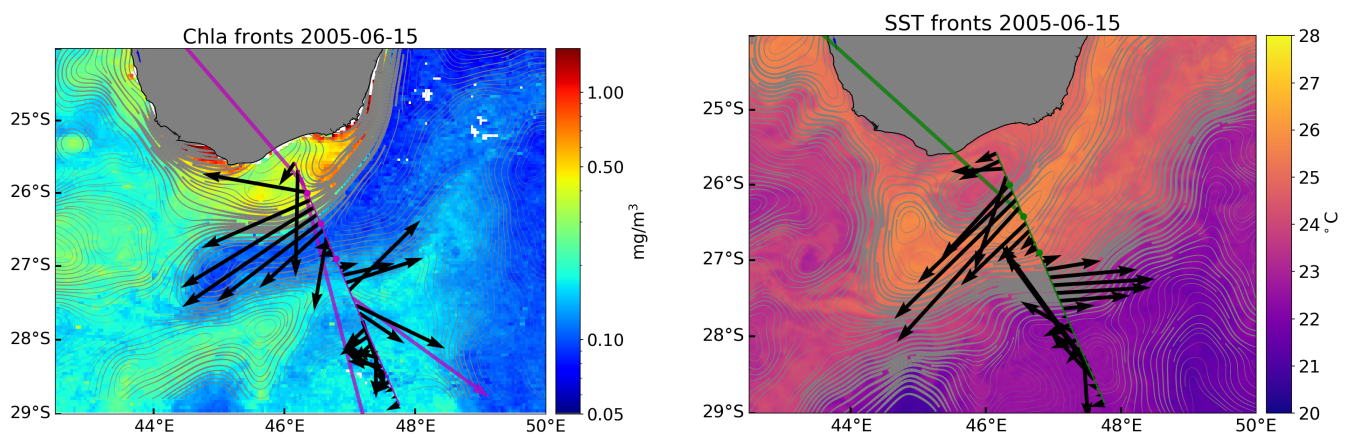

Figure 8: Example of total velocity vectors, $\boldsymbol{V}$, reconstructed along the J1-196 track for 15 June 2005. $V_{\text {across }}$ is the same as in Figure 2. $V_{\text {along }}$ has been computed using equation 1. Chlorophyll and SST fields and associated grey contours are identical to Figure 2. Magenta and green vectors are the ones removed by applying the $V_{\text {along }}$ thresholds (see Figure 9 ).

paragraph, even using more restrictive thresholds do not entirely resolve the limitations of the proposed approach. Overall, the $V_{\text {along }}$ threshold is more conservative at high angles, where if $V_{\text {across }}$ is small, large values of $V_{\text {along }}$ can still contribute to total velocities below the $\|\boldsymbol{V}\|$ threshold; on the other hand, the $\|\boldsymbol{V}\|$ threshold is more conservative at low angles, where if $V_{\text {across }}$ is large, reconstructed $V_{\text {along }}$ below the $V_{\text {along }}$ threshold can still contribute to total velocities larger than the $\|\boldsymbol{V}\|$ threshold. Overall, $83 \%$ of the $V_{\text {along }}$ reconstructed from chlorophyll concentration and $84 \%$ from SST are below the in-situ defined threshold values.

Removing the reconstructed $V_{\text {along }}$ outside the range of in-situ observations slightly improves the correlation between the observed and reconstructed $V_{\text {along }}$ (Figure 10). The RMS drops significantly to values of the same order as those observed for the combined mapped products $(\sim 0.2 \mathrm{~m}$ $\mathrm{s}^{-1}$, not shown). At the same time, especially for $V_{\text {along }}$, the correlation coefficients remain quite low and the regression lines quite different from the 1:1 

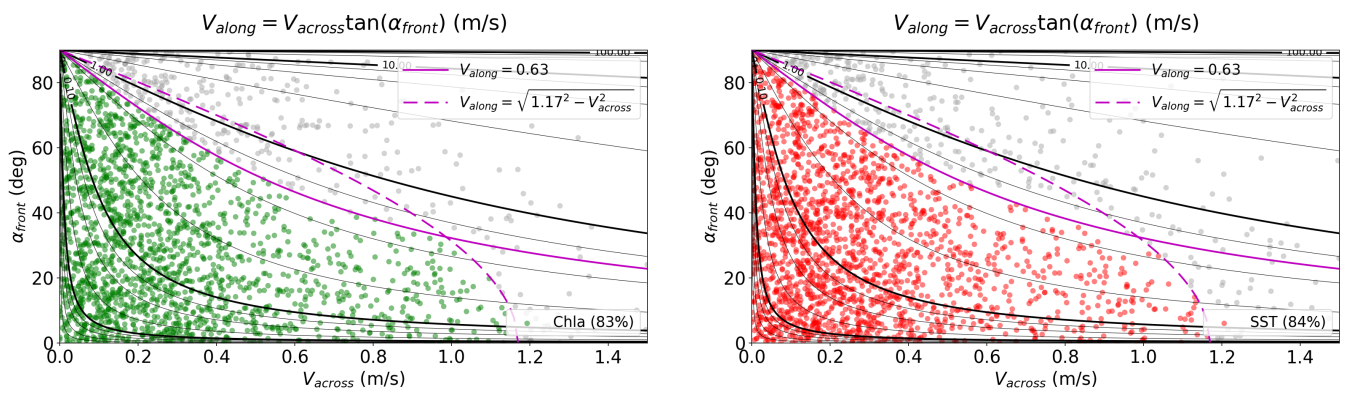

Figure 9: Distribution of the observed along-track $V_{\text {across }}$ and the associated $\alpha_{\text {front }}$ used for the analysis. Left panel are the values from chlorophyll concentration; right panel those from SST. Black contours mark the values of $V_{\text {along }}$ reconstructed from equation 1 . Thick contours indicate values for successive powers of 10 from 0.01 to $100 \mathrm{~m} \mathrm{~s}^{-1}$. Solid and dashed magenta lines are the $V_{\text {along }}$ thresholds based, respectively, on the maximum value of $V_{\text {along }}$ and total velocity magnitude from the moving-averaged ADCP observations. Grey circles mark the combinations of $V_{\text {across }}$ and $\alpha_{\text {front }}$ for which the reconstructed $V_{\text {along }}$ are outside the range of in-situ observations.

correlation. This can only be partly explained by the fact that not all the $V_{\text {along }}$ from along-flow fronts can be removed by imposing the ADCP-based thresholds (Figure 8). Indeed, the main issue is due to the errors associated with $V_{\text {along }}$ reconstructed for high $\alpha_{\text {front }}$ values.

Figure 11 shows how the uncertainties in $\alpha_{\text {front }}\left(\Delta \alpha_{\text {front }}\right)$ observed in Section 2.4 affect the values of $V_{\text {along }}$ reconstructed for different combinations of $V_{\text {across }}$ and $\alpha_{\text {front }}$. As shown in Section 3.1, such uncertainties have the largest impact on the accuracy of the reconstructed $V_{\text {along }}$. The $V_{\text {along }}$ error associated with such uncertainties can be defined as

$$
\delta V_{\text {along }}=\left|\frac{\partial\left(V_{\text {across }} \tan \alpha_{\text {front }}\right)}{\partial \alpha_{\text {front }}} \delta \alpha_{\text {front }}\right|=\left|V_{\text {across }} \frac{\delta \alpha_{\text {front }}}{\left(\cos \alpha_{\text {front }}\right)^{2}}\right|
$$

Because equation 1 involves the tangent of $\alpha_{\text {front }}, \delta V_{\text {along }}$ grows quite 

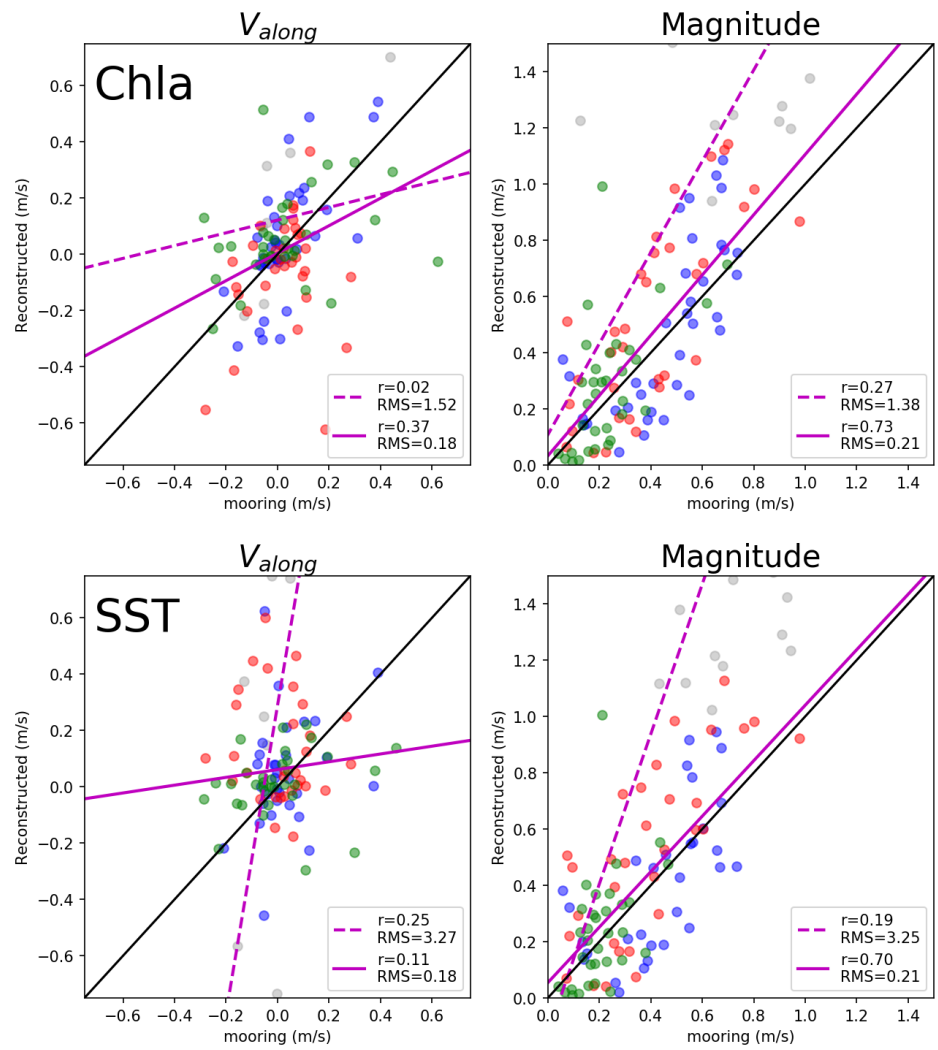

Figure 10: Correlations between observed and reconstructed $V_{\text {along }}$ (left column) and $\|\boldsymbol{V}\|$ (right column) at the location of the three moorings. Top row are velocities reconstructed from chlorophyll front directions; bottom row from SST front directions. Circle colours identify the various moorings as in Figure 3. Grey circle are the observations discarded according to the thresholds shown in Figure 9. In each panel, the black line indicates the 1:1 regression line; the dashed magenta line indicates the regression line obtained from all data; the solid magenta line indicates the regression line obtained from the data within the thresholds, only. Note that some of the values used for the fit are outside the axes limits. Correlation coefficient (r) and root mean square error (RMS) are indicated in each panel legend. 

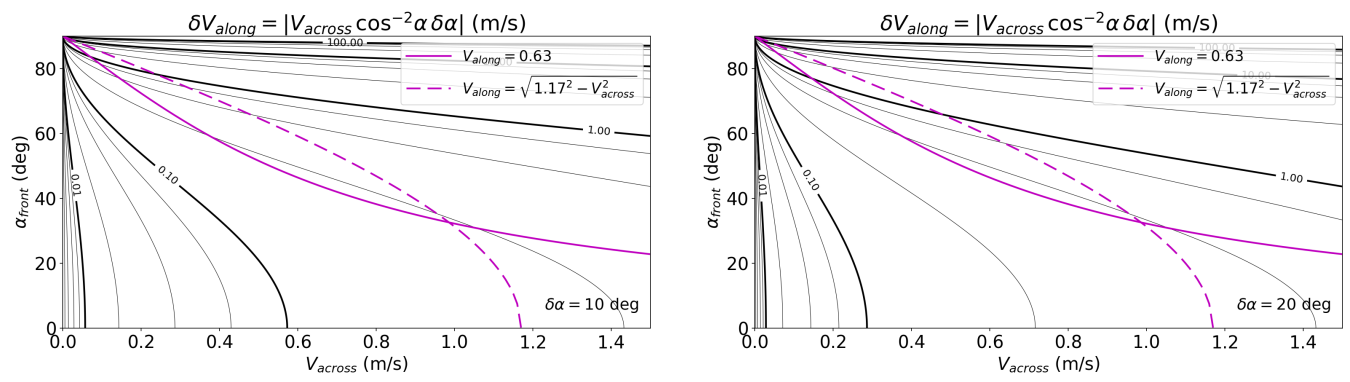

Figure 11: Variation of the error associated to the reconstructed $V_{\text {along }}\left(\mathrm{m} \mathrm{s}^{-1}\right.$, black contours) as a function of $V_{\text {across }}$ and $\alpha_{\text {front }}$ for different $\alpha_{\text {front }}$ uncertainties, $\delta \alpha_{\text {front }}$. As in Figure 9, solid and dashed magenta lines indicate the $V_{\text {along }}$ thresholds based, respectively, on the maximum value of $V_{\text {along }}$ and $\|\boldsymbol{V}\|$ from the moving-averaged ADCP observations.

rapidly for high values of $\alpha_{\text {front }}$; that is, when front directions become almost parallel to the satellite track. High front directions are usually associated with weaker $V_{\text {across }}$ and stronger $V_{\text {along }}$. As a direct consequence, the proposed approach is characterised by the inherent limitation (already mentioned in Section 3.1 when $V_{\text {along }}$ were reconstructed using $\alpha_{A D C P}$ ) of being quite accurate in retrieving total velocities when they are almost perpendicular to the satellite track (that is, when $V_{\text {across }}$ are strong and the corrections due to $V_{\text {along }}$ small) and not accurate when total velocities are almost parallel to the satellite track (that is, when $V_{\text {across }}$ are weak and the corrections due to $V_{\text {along }}$ large).

\subsection{An alternative approach}

Based on these observations, to mitigate the presence of artifacts in the reconstructed $V_{\text {along }}$, we decided to further modify our approach and base the reconstruction only on the strongest fronts. This new approach was 
tested on the fronts obtained from OC_CCI chlorophyll fields. The strongest fronts were identified as along-track local maxima (within an interval of 70 $\mathrm{km}$, corresponding to 5 successive observations) of the total gradient magnitude (Figure 12, bottom left). To compute $V_{\text {along }}$, it was then necessary to reconstruct the full along-track profile of $\alpha_{\text {front }}$ by filling the gaps between the values associated with the strongest fronts. As a first test, we decided to use a simple linear interpolation (Figure 12 bottom right). Information from the satellite $V_{\text {across }}$ was integrated in the interpolation. In particular, as the region is characterised by alternating currents of almost opposite direction, the points of zero-crossing of satellite $V_{\text {across }}$ (Figure 12, bottom centre-left) were used to define the positions at which the current direction was averaged between those at the preceding and following local maxima (Figure 12 bottom right). Although actual current directions at zero-crossing points can be slightly different, the inaccuracies introduced by this assumption do not result in large errors on the reconstructed $V_{\text {along }}$, because the $V_{\text {across }}$ values within those regions are usually small. The full profile of $\alpha_{\text {front }}$ was then computed by interpolating the values associated with either two successive front maxima or a front maximum and a $V_{\text {across }}$ zero-crossing.

To remove most of the unrealistically high $V_{\text {along }}\left(>1 \mathrm{~m} \mathrm{~s}^{-1}\right)$, while at the same time retaining most of the acceptable ones (see Figures 6 and 9), a threshold of $60^{\circ}$ was imposed on the reconstructed $\alpha_{\text {front }}$. Along-track points with $\left|\alpha_{\text {front }}\right|>60^{\circ}$ (156 points over 2256, $6.9 \%$ of the total in the two-year span considered) were removed from the analysis, and the resulting gaps filled with a second linear interpolation. The reconstructed along-track profile of $\alpha_{\text {front }}$ was then used to compute new estimates of $V_{\text {along }}$ (Figure 12, bottom 

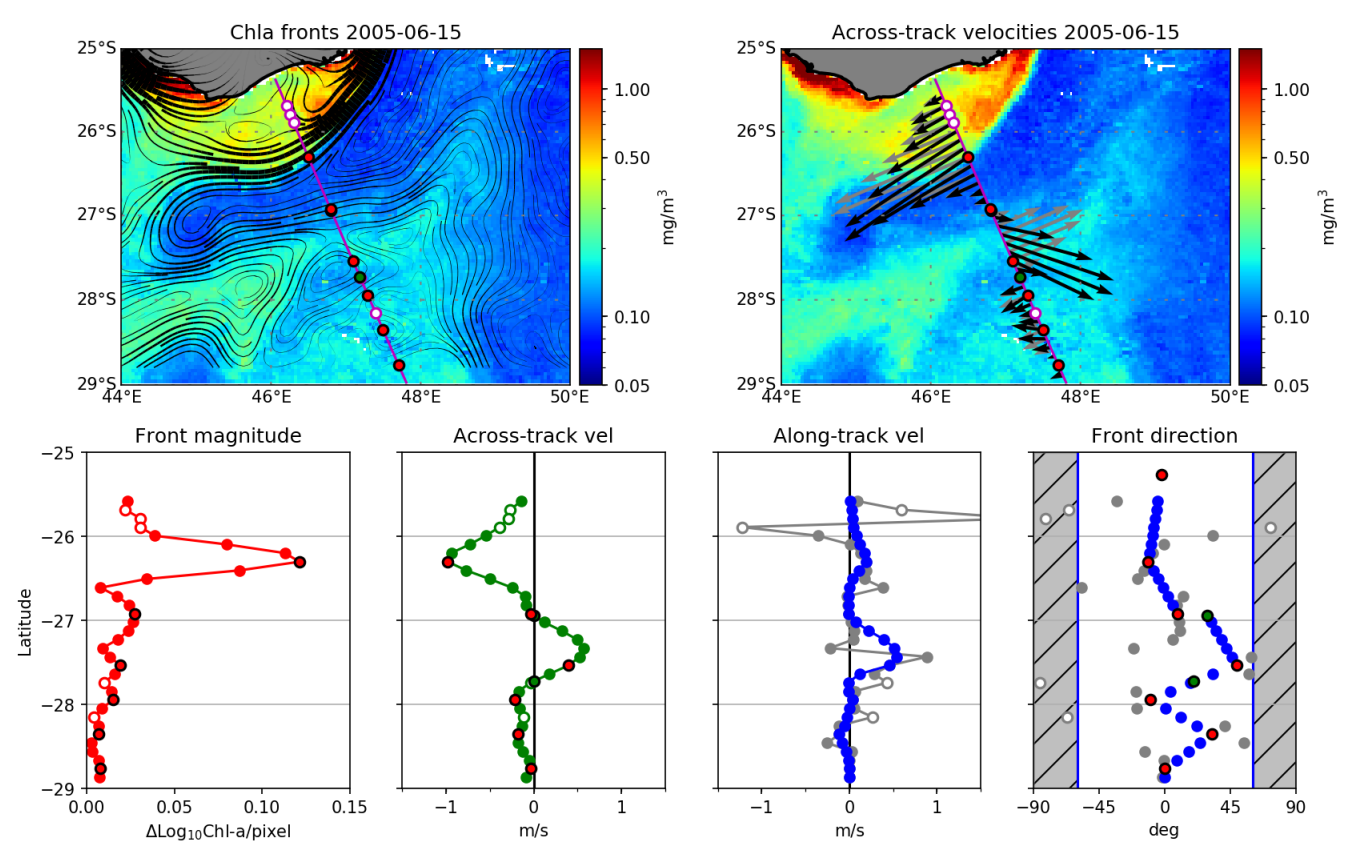

Figure 12: (Top left) Contour lines indicating the direction of the chlorophyll fronts analogous to Figure 2, bottom. As in Figure 8, these are superimposed on the 7-day composite map of chlorophyll concentration. The circles along the J1-196 track indicate the position of: local maxima of front intensity (red); points of across-track velocity crossing (green); absolute front directions larger than $60^{\circ}$ (white). This is valid for all panels in the figure. (Top right) Same chlorophyll map with superimposed the across-track, $V_{\text {across }}$, and reconstructed total velocities from the interpolated front directions, $\boldsymbol{V}$, (grey and black vectors, respectively) for June 15, 2005. (Bottom left to right) Along-track front magnitude, satellite across-track velocities $\left(V_{\text {across }}\right)$, estimated along-track velocities $\left(V_{\text {along }}\right)$ and front directions $\left(\alpha_{\text {front }}\right)$. In the centre-right and right panels, $V_{\text {along }}$ from original and interpolated $\alpha_{\text {front }}$, and original and interpolated $\alpha_{\text {front }}$ are in grey and blue, respectively. Shaded areas in the right panel mark the boundaries where $\left|\alpha_{\text {front }}\right|>60^{\circ}$.

centre-right). As shown by the plot, the along-track distribution of the new

$V_{\text {along }}$ is not characterised by the unrealistic spikes obtained using the original 
Total velocity from $\alpha_{\text {front }}$

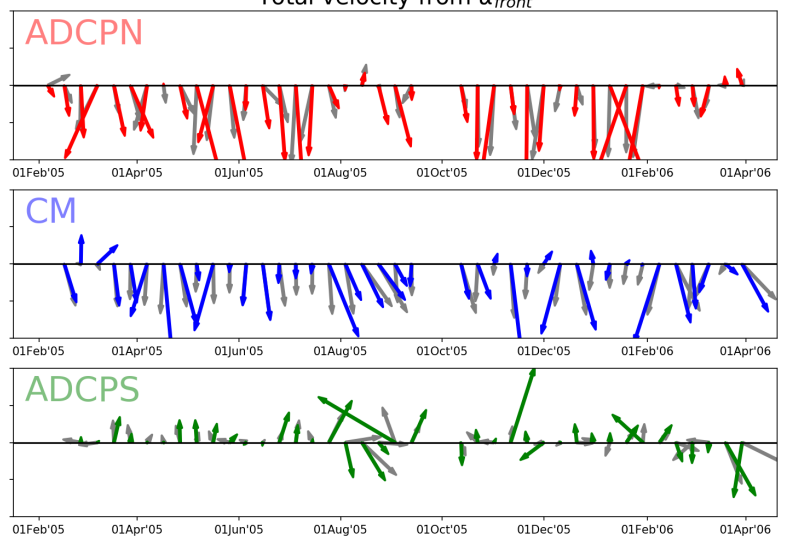

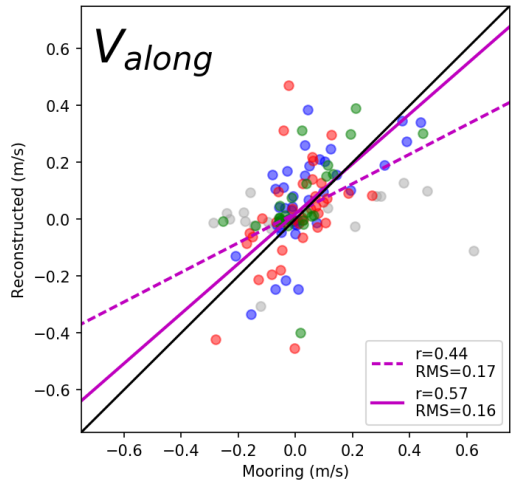

Figure 13: (Left) Same as Figure 7, but for $\boldsymbol{V}$ reconstructed using $V_{\text {across }}$ from satellite observations and $V_{\text {along }}$ computed from equation 1, combining $V_{\text {across }}$ and the front direction, $\alpha_{\text {front }}$. (Right) Correlation between $V_{\text {along }}$ observed at the moorings and the ones reconstructed using $\alpha_{\text {front }}$. Dashed magenta line represents the linear fit using all data; as in Figure 7, solid magenta line represents the fit using only the points with $\left|\alpha_{A D C P}\right| \leq 60^{\circ}$. Note that some of the values used for the fit are outside the axes limits. The colours identify the various moorings as in Figure 3.

$\alpha_{\text {front }}$ profile. Moreover, the resulting $\boldsymbol{V}$ vectors (Figure 12, top right) are not affected by patterns of divergence/convergence as in Figure 8, while at the same time they remain consistent with the structures of the underlying surface chlorophyll field. Thus, although the proposed approach still results in inaccurate $V_{\text {along }}$ at high incidence angles, the overall the accuracy of the reconstructed $V_{\text {along }}$ is improved, allowing us to retain the reconstructed values of $V_{\text {along }}$ for the whole length of the satellite track.

As in Section 3.1, a more quantitative evaluation of the performances of our approach was obtained by directly comparing the reconstructed $V_{\text {along }}$ with the ones directly measured at the three mooring sites (Figure 13). The 
three time-series of $\boldsymbol{V}$ show good agreement between reconstructed and observed velocities (especially for the ADCPN and CM moorings), indicating that the approach returns reliable velocity directions $\left(\alpha_{\text {front }} \approx \alpha_{A D C P}\right)$. The largest discrepancies are observed in the ADCPS time-series, characterised by smaller $V_{\text {across }}$ and higher $\alpha_{A D C P}$. However, the time-series do not show the large values in $\boldsymbol{V}$ reconstructed at high $\alpha_{A D C P}$ shown in Figure 7 . Thus, by reducing the differences between observed and reconstructed velocities at high $\alpha_{A D C P}$, this modified approach effectively mitigates some of the limitations described $\mathrm{n}$ the previous sections.

Correlations between observed and reconstructed $V_{\text {along }}$ for the three moorings (Figure 13, right) show that the best fit occurs for $\mathrm{CM}(\mathrm{r}=0.66$, not shown). Among the three moorings, $\mathrm{CM}$ is the closest to the average location of the strong chlorophyll front between coastal and open ocean waters, and thus it is likely to be characterised by the most accurate estimates of $\alpha_{\text {front }}$. On the other hand, the worst fit occurs for the ADCPS mooring $(r=0.32)$. The mooring is located in a region often characterised by recirculation structures associated with weaker velocities intersecting the J1-196 track at higher angles than at the other two sites. Also, some of the surface circulation might be decoupled from that at $140 \mathrm{~m}$. Overall, the new approach returns a fit for all $V_{\text {along }}$ with correlation and RMS (0.44 and 0.17, respectively) analogous to those observed in Figure 10 using only the data within the thresholds. As in Figure 7, by removing the values of $V_{\text {along }}$ obtained for $\left|\alpha_{A D C P}\right|>60^{\circ}$, the fit for the reconstructed $V_{\text {along }}$ improves even more. Although the correlation coefficients remain lower than the one observed for the idealized case, the computed correlation lines become more aligned with the 1:1 line, and both 
correlation coefficient and RMS error improve.

\section{Conclusions and Recommendations}

This study explored the possibility to combine across-track velocities from along-track altimetry $\left(V_{\text {across }}\right)$ with front directions from surface tracer observations $\left(\alpha_{\text {front }}\right)$ to retrieve along-track components $\left(V_{\text {along }}\right)$ and hence total velocities $(\boldsymbol{V})$. The key questions that this study aimed at addressing include the accuracy and spatial resolution at which $\boldsymbol{V}$ can be reconstructed along an altimeter track from such a synergistic approach. A method to reconstruct $V_{\text {along }}$ was proposed, so that the resulting $\boldsymbol{V}$ has direction parallel to the front and the same across-track component as measured from altimetry. The method was applied to altimetry observations along the J1-196 track in the south Madagascar region. The reconstructed $V_{\text {along }}$ were compared with observations collected from 3 moorings between February 2005 and April 2006 along the same track.

The results indicate that directions of tracer fronts can be successfully used to retrieve accurate information on surface currents. $V_{\text {along }}$ estimates from equation 1 are accurate for small angles $\left(\left|\alpha_{\text {front }}\right| \leq 60^{\circ}\right)$, with RMS of the same order as those observed for altimetry-based $V_{\text {across }}$ or reported in previous studies (e.g. Rio et al., 2014). At the same time, errors rapidly grow for $\left|\alpha_{\text {front }}\right|>60^{\circ}$. This can be particularly constraining for the reconstruction of total velocities associated with the passage of mesoscale eddies, when, due to the rotating vectors, high incidence angles are likely to occur. Our analysis revealed several aspects that also pose substantial limitations to the spatial resolution at which $\boldsymbol{V}$ can be reconstructed. These include: a) the horizon- 
tal gradients derived from surface tracer fields require some smoothing; $b$ ) only reliable front directions should be used in the analysis (e.g. along-flow fronts should be excluded from the analysis). c) uncertainties associated with front-derived velocity direction can be large and strongly depend on the characteristics of the region of study. Thus, while surface tracer can be used to improve the accuracy of the large-scale and mesoscale flow (e.g. Rio et al., 2016), they currently remain of limited use to reconstruct smaller scale currents.

Reducing the uncertainty associated with front-derived velocity direction represents the first step for more accurate reconstructed $V_{\text {along }}$. In this perspective, more advanced methods for the identification of surface fronts, such as singularity exponent analysis (e.g. Isern-Fontanet et al., 2007; Turiel et al., 2009), could significantly improve the proposed approach as they have the potential to provide more accurate directional information. However, it is unclear whether they will be able to mitigate the issues associated with the along-flow fronts. More advanced interpolation methods of $\alpha_{\text {front }}$ along the satellite track, as well as a more explicit combined integration of the directional information from chlorophyll and SST fields, would also improve the accuracy of the reconstructed $V_{\text {along }}$ and would enhance the effective spatial resolution at which dynamical information can be retrieved.

The major limitation of the proposed approach remains the one related to errors in $V_{\text {along }}$ associated with high-front angles. This is quite undesirable since it means that small $V_{\text {along }}$ are accurate while larger $V_{\text {along }}$ (usually associated with $\left|\alpha_{\text {front }}\right|>60^{\circ}$ ) are not. Error analysis of the $V_{\text {along }}$ errors (equation 2) showed that such errors are intrinsic to this specific approach. 
Although restricting the value of $\left|\alpha_{\text {front }}\right|$ to $\leq 60^{\circ}$ reduced the overall error of $V_{\text {along }}$, different approaches should be explored to retrieve more accurate $V_{\text {along }}$ for larger $\alpha_{\text {front }}$.

Further testing of future approaches should not be limited to the south Madagascar region. Availability of in-situ ADCP observations is not mandatory for the validation, since total geostrophic velocities derived at satellite cross-overs could be used instead. Therefore, results from the present study (as well as development of future approaches) could be further generalized by extending their application to other regions with similar favourable conditions as the south Madagascar region (e.g. Agulhas Current and other western boundary currents).

\section{Acknowledgements}

This work was funded by the European Space Agency through the GlobCurrent project. The authors would like to thank the other members of the GlobCurrent consortium for the productive discussions and suggestions throughout the development of this study.

\section{References}

Arbic, B. K., Scott, R. B., Chelton, D. B., Richman, J. G., Shriver, J. F., 2012. Effects of stencil width on surface ocean geostrophic velocity and vorticity estimation from gridded satellite altimeter data. J. Geophys. Res. 117 (C3), C03029.

Bojinski, S., Verstraete, M., Peterson, T. C., Richter, C., Simmons, A., Zemp, M., 2014. The concept of essential climate variables in support of 
climate research, applications, and policy. B. Am. Meteorol. Soc. 95 (9), 1431-1443.

Bowen, M. M., Emery, W. J., Wilkin, J. L., Tildesley, P. C., Barton, I. J., Knewtson, R., 2002. Extracting multiyear surface currents from sequential thermal imagery using the maximum cross-correlation technique. J. Atmos. Ocean. Tech. 19 (10), 1665-1676.

Capet, X., McWilliams, J. C., Molemaker, M. J., Shchepetkin, A. F., 2008. Mesoscale to submesoscale transition in the California current system. Part III: Energy balance and flux. J. Phys. Oceanogr. 38 (10), 2256-2269.

Chavanne, C. P., Klein, P., 2010. Can oceanic submesoscale processes be observed with satellite altimetry? Geophys. Res. Lett. 37.

Chelton, D. B., Schlax, M. G., Samelson, R. M., 2011. Global observations of nonlinear mesoscale eddies. Prog. Oceanogr. 91 (2), 167 - 216.

Chen, W., Mied, R. P., Shen, C. Y., 2008. Near-surface ocean velocity from infrared images: Global Optimal Solution to an inverse model. J. Geophys. Res. 113 (C10), C10003.

Côte, S., Tatnall, A. R. L., 1997. The Hopfield neural network as a tool for feature tracking and recognition from satellite sensor images. Int. J. Remote Sens. 18 (4), 871-885.

Cotté, C., d'Ovidio, F., Dragon, A.-C., Guinet, C., Lévy, M., 2015. Flexible preference of southern elephant seals for distinct mesoscale features within the Antarctic Circumpolar Current. Prog. Oceanog. 131, 46-58. 
de Ruijter, W. P., van Aken, H. M., Beier, E. J., Lutjeharms, J. R., Matano, R. P., Schouten, M. W., 2004. Eddies and dipoles around South Madagascar: formation, pathways and large-scale impact. Deep Sea Res. Part I $51(3), 383-400$.

d'Ovidio, F., De Monte, S., Alvain, S., Dandonneau, Y., Lévy, M., 2010. Fluid dynamical niches of phytoplankton types. Proc. Natl. Acad. Sci. U. S. A. 107 (43), 18366-18370.

d’Ovidio, F., Isern-Fontanet, J., López, C., Hernández-García, E., GarcíaLadona, E., 2009. Comparison between Eulerian diagnostics and finite-size Lyapunov exponents computed from altimetry in the Algerian basin. Deep Sea Res. I 56 (1), 15-31.

Dufau, C., Orsztynowicz, M., Dibarboure, G., Morrow, R., Le Traon, P.-Y., 2016. Mesoscale resolution capability of altimetry: Present and future. J. Geophys. Res. 121 (7), 4910-4927.

Ganachaud, A., Wunsch, C., 2000. Improved estimates of global ocean circulation, heat transport and mixing from hydrographic data. Nature 408 (6811), 453-457.

Grant, M., Jackson, T., Chuprin, A., Sathyendranath, S., Zuhlke, M., Storm, T., Boettcher, M., Fomferra, N., 2015. Product user guide, Ocean Color Climate Change Initiative (OC_CCI)-Phase two. Tech. Rep. D3.4 PUG, European Space Agency, Frascati, Italy, available at http://www.esaoceancol-our-cci.org/?q=webfm_send/496. 
Isern-Fontanet, J., Ballabrera Poy, J., Turiel, A., García Ladona, E., 2017. Remote sensing of ocean surface currents: a review of what is being observed and what is being assimilated. Nonlinear Processes in Geophysics $24(4), 613-643$.

Isern-Fontanet, J., Shinde, M., González-Haro, C., 2014. On the transfer function between surface fields and the geostrophic stream function in the Mediterranean Sea. J. Phys. Oceanogr. 44 (5), 1406-1423.

Isern-Fontanet, J., Turiel, A., Garca-Ladona, E., Font, J., 2007. Microcanonical multifractal formalism: Application to the estimation of ocean surface velocities. J. Geophys. Res. 112 (C5), C05024.

Jones, M. S., Allen, M., Guymer, T., Saunders, M., 1998. Correlations between altimetric sea surface height and radiometric sea surface temperature in the South Atlantic. J. Geophys. Res. 103 (C4), 8073-8087.

Jönsson, B. F., Watson, J. R., 2016. The timescales of global surface-ocean connectivity. Nat. Commun. 7, 11239.

JPL MUR MEaSUREs Project, 2015. GHRSST Level 4 MUR Global Foundation Sea Surface Temperature Analysis (v4.1). Ver. 4.1. PO.DAAC, CA, USA.

Lapeyre, G., Klein, P., 2006. Dynamics of the upper oceanic layers in terms of surface quasigeostrophy theory. J. Phys. Oceanogr. 36 (2), 165-176.

Le Traon, P. Y., 2013. From satellite altimetry to Argo and operational oceanography: three revolutions in oceanography. Ocean Science 9 (5), 901-915. 
Le Traon, P. Y., Nadal, F., Ducet, N., 1998. An improved mapping method of multisatellite altimeter data. J. Atmos. Ocean. Tech. 15 (2), 522-534.

Lehahn, Y., d'Ovidio, F., Levy, M., Heifetz, E., 2007. Stirring of the northeast Atlantic spring bloom: A Lagrangian analysis based on multisatellite data. J. Geophys. Res. 112 (C8), C08005.

Mahadevan, A., 2016. The impact of submesoscale physics on primary productivity of plankton. Annual Review of Marine Science 8 (1), 161-184.

Quartly, G. D., 2006. RRS Discovery Cruise 288, 26 Jan - 21 Feb 2005. Madagascar Experiment (MadEx), NOC Cruise Report, 8. (105pp.) Available at: https://eprints.soton.ac.uk/42070/.

Quartly, G. D., Buck, J. J. H., Srokosz, M. A., Coward, A. C., 2006. Eddies around Madagascar The retroflection re-considered. J. Marine Syst. 63 (34), $115-129$.

Quartly, G. D., Srokosz, M. A., 2002. SST Observations of the Agulhas and East Madagascar Retroflections by the TRMM Microwave Imager. J. Phys. Oceanogr. 32 (5), 1585-1592.

Quartly, G. D., Srokosz, M. A., 2003. Satellite observations of the Agulhas Current system. Phil. Trans. R. Soc. A 361 (1802), 51-56.

Quartly, G. D., Srokosz, M. A., 2004. Eddies in the southern Mozambique Channel. Deep Sea Res. Part II 51 (1), $69-83$.

Rio, M.-H., Mulet, S., Picot, N., 2014. Beyond GOCE for the ocean circulation estimate: Synergetic use of altimetry, gravimetry, and in situ data 
575 provides new insight into geostrophic and Ekman currents. Geophys. Res. $576 \quad$ Lett. 41, 8918-8925.

Rio, M.-H., Santoleri, R., Bourdalle-Badie, R., Griffa, A., Piterbarg, L., Taburet, G., 2016. Improving the altimeter derived surface currents using high resolution sea surface temperature data: A feasability study based on model outputs. J. Atmos. Oceanic Technol. 33 (12), 2769-2784.

SSALTO/DUACS User Handbook, 2016. (M)SLA and (M)ADT near-real time and delayed time products. CLS-DOS-NT-06-034.

Turiel, A., Nieves, V., Garcia-Ladona, E., Font, J., Rio, M.-H., Larnicol, G., 2009. The multifractal structure of satellite sea surface temperature maps can be used to obtain global maps of streamlines. Ocean Science 5 (4), 447-460.

Warren, M. A., Quartly, G. D., Shutler, J. D., Miller, P. I., Yoshikawa, Y., 2016. Estimation of ocean surface currents from maximum cross correlation applied to GOCI geostationary satellite remote sensing data over the Tsushima (Korea) Straits. J. Geophys. Res. 121 (9), 6993-7009. 